\title{
Experimental determination of the heat transfer coefficient in shell-and-tube condensers using the Wilson plot method
}

\author{
Jan Havlik ${ }^{1, *}$, Tomas Dlouhy ${ }^{1}$ \\ ${ }^{1}$ Czech Technical University in Prague, Faculty of Mechanical Engineering, Department of Energy Engineering,, Technicka 4, \\ 16607 Prague 6, Czech Republic
}

\begin{abstract}
This article deals with the experimental determination of heat transfer coefficients. The calculation of heat transfer coefficients constitutes a crucial issue in design and sizing of heat exchangers. The Wilson plot method and its modifications based on measured experimental data utilization provide an appropriate tool for the analysis of convection heat transfer processes and the determination of convection coefficients in complex cases. A modification of the Wilson plot method for shell-and-tube condensers is proposed. The original Wilson plot method considers a constant value of thermal resistance on the condensation side. The heat transfer coefficient on the cooling side is determined based on the change in thermal resistance for different conditions (fluid velocity and temperature). The modification is based on the validation of the Nusselt theory for calculating the heat transfer coefficient on the condensation side. A change of thermal resistance on the condensation side is expected and the value is part of the calculation. It is possible to improve the determination accuracy of the criterion equation for calculation of the heat transfer coefficient using the proposed modification. The criterion equation proposed by this modification for the tested shell-and-tube condenser achieves good agreement with the experimental results and also with commonly used theoretical methods.
\end{abstract}

\section{Introduction}

The heat transfer mechanism by convection is an energy transfer between a solid surface and a moving fluid induced by a temperature difference between the solid surface and the fluid. Heat transfer by convection is indeed a combination of conduction and fluid motion. The analytical treatment of convection problems requires the solution of a system of mass, momentum and energy conservation equations. Although these procedures are elaborate, analytic solutions are available for simple geometries under restrictive assumptions. Most of the convective heat transfer processes inherent to heat exchangers usually involve complex geometries and complicated flows so analytical solutions are not possible. Therefore, an approach based on Newton's law of cooling (see Eq. (1)), provides a simple alternate technique. Newton's law of cooling established an algebraic relation between the heat flow by convection $Q$, the surface area $A$, the heat transfer coefficient $h$ and the temperature difference between the solid surface $T_{s}$ and the fluid $T_{f}$.

$$
Q=h \cdot\left(T_{f}-T_{s}\right) \cdot A
$$

For a given flow and surface geometry, the experimental data is usually obtained by measuring the surface and fluid temperatures. Then the heat transfer coefficient (HTC) may be calculated from Eq. (1).
However, the main difficulty of this methodology lies in the measurement of the surface temperature, because the surface temperature varies from point to point, and the flow profile could be altered by the presence of the temperature sensors. Moreover, in many cases of heat exchangers the heat transfer surface is not accessible. Therefore, any alternative method conducive to the HTC calculation is attractive because of widespread use and practical applications [1].

\section{Wilson plot method}

The Wilson plot method is used for the experimental determination of the HTC or coefficients of a criterion equation, which describes the HTC calculation. This method avoids the direct measurement of the surface temperature and consequently any disturbance of the fluid flow and heat transfer introduced while attempting to measure those temperatures. Therefore, the method constitutes a suitable technique for estimating HTCs in a variety of convective heat transfer processes [1].

The original method has been derived for the processes of transferring heat by convection, when the thermal resistance on one side of the heat transfer surface remains constant (in the case of condensation[2]) while varying the mass flow on the other side changes the total thermal resistance in the heat exchanger. This relies on the fact that the overall thermal resistance can be taken from experimental measurements in a reliable

Corresponding author: jan.havlik@fs.cvut.cz 
manner [1]. This method was originally derived for determining the coolant HTC in steam condensers where steam condenses outside the tubes and the coolant flows inside. The sensitivity of the coolant HTC value to the overall HTC is more significant than the condensation HTC [2]. The mean value of the HTC on the coolant side can be described as a function of the speed of the coolant [1].

The aim of the method is to calculate the convection coefficients (or thermal resistance) of the fluid in the criterion equation for the defined type of convection heat transfer. Modifications of the Wilson plot method were proposed to enhance its accuracy. The principle of the original method is still maintained. The application of the Wilson plot method is based on the measurement of the experimental mass flow rate and temperatures.

\section{Tested heat exchanger}

The tested heat exchanger is a vertical shell-and-tube model in which the condensing water vapour flows downwards inside vertical tubes and the cooling water flows in a counter current in the outer shell (see Fig. 1). The shell side has a complex geometry with complicated flow patterns so using the Wilson plot method is suitable for determining the shell-side HTC.

The tube bundle is formed by 49 tubes $865 \mathrm{~mm}$ in length, $28 \mathrm{~mm}$ in external diameter and $24 \mathrm{~mm}$ in internal diameter. The tubes are arranged in staggered arrays with a triangular tube pitch of $35 \mathrm{~mm}$. The crosssection of the shell is rectangular in shape, $223 \mathrm{~mm}$ by $270 \mathrm{~mm}$ in size. Seven segmental baffles $(223 \times 230 \mathrm{~mm})$ are used in the shell section. The tubes are made from stainless steel 1.4301 (AISI 304).
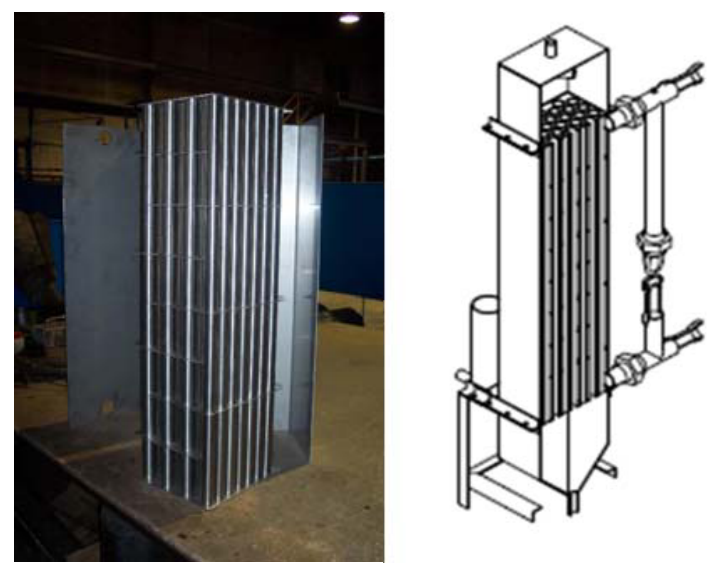

Fig. 1. Vertical tube condenser

The testing loop is shown in Fig. 2. Steam is produced in a steam generator. Before the steam enters the vertical tube condenser, its parameters are reduced to the required values. Hot water recirculation enables the cooling water temperature and the cooling water flow rate in the condenser to be regulated. The measured parameters are the inlet cooling water temperature $T_{w 1}$, the temperature of the water after recirculation $T_{w 2}$, the outlet cooling water temperature $T_{w 3}$, the cooling water flow rate $Q_{w}$, the inlet steam pressure $p_{s}$, the inlet steam temperature $T_{s}$ and the amount of steam condensate $M_{c}$.

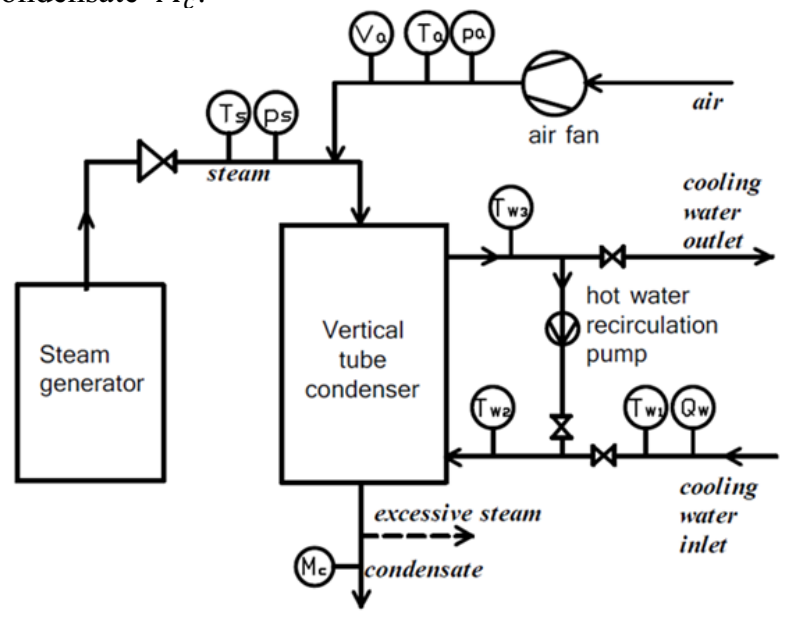

Fig. 2. Scheme of the testing loop

\section{Original Wilson Plot method}

Derivation of the Wilson-plot is well described in [1]. The overall thermal resistance of the condensation process in a shell-and-tube condenser $R_{o v}$ can be expressed as the sum of three thermal resistances corresponding to the internal convection $R_{i}$, the tube wall $R_{S}$ and the external convection $R_{o}$ as

$$
R_{o v}=R_{i}+R_{s}+R_{o}
$$

For the sake of simplicity, the thermal resistances of the fluid fouling are neglected. Wilson theorized that if the mass flow of the cooling liquid was modified, then the change in the overall thermal resistance would be mainly due to the variation of the coolant HTC, while the remaining thermal resistances remained nearly constant. The HTC varies with the fluid mass flow for many cases of the convection heat transfer process excluding the phase changes. It is valid also for complex heat exchanger geometries. An illustrative example of the experimental determined dependence of the HTC on the fluid mass flow is well described in [3].

Therefore, the thermal resistances on the condensation side and the tube wall could be considered constant. In the case of a condenser where steam condenses inside the tubes is considered

$$
R_{i}+R_{S}=C_{1}
$$

where $C_{1}$ is a constant. For the thermal resistance on the cooling water side $R_{o}$ is considered

$$
R_{o}=\frac{1}{h A}
$$

where $A$ is the heat surface area and the HTC on the cooling water side $h$ is proportional to the power of the fluid velocity $v$

$$
h=C_{2} \cdot v^{n}
$$

where $C_{2}$ is a constant and $n$ is the velocity exponent. 
Upon combining Eq. (2), Eq. (3), Eq. (4) and Eq. (5), the overall thermal resistance turns out to be a linear function of $v^{n}$

$$
R_{o v}=\frac{1}{C_{2} A} \cdot \frac{1}{v^{n}}+C_{1}
$$

This is presented graphically in Fig. 3.

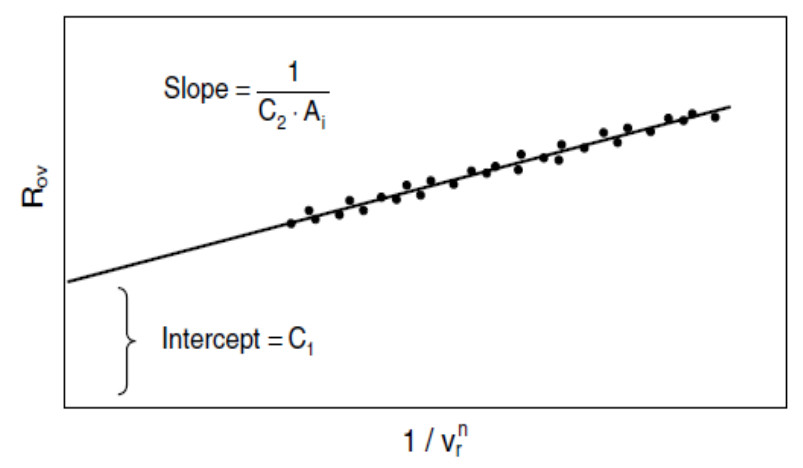

Fig. 3. A linear function of the thermal resistance [1]

From here, the straight line equation that fits the experimental data can be deduced by applying simple linear regression. The overall thermal resistance may be expressed as a function of the overall heat transfer coefficient $U$ and surface area $A$

$$
R_{o v}=\frac{1}{U \cdot A}
$$

Then, for each set of experimental data corresponding to each mass flow rate, the overall thermal resistance is provided by substituting Eq. (7) to Eq. (7). This equation describes the calculation of the overall heat transfer coefficient from the performance of the heat exchanger and the logarithmic mean temperature difference of the fluids $\Delta T_{\log }$

$$
U=\frac{Q}{A \cdot \Delta T_{\log }}
$$

The heat exchanger performance $Q$ is provided by the equation

$$
Q=M_{w} \cdot c_{w} \cdot\left(T_{w, o u t}-T_{w, \text { in }}\right)
$$

where $M_{w}$ is the cooling water flow, $c_{w}$ is the specific heat capacity of water, $T_{w, o u t}$ is the outlet cooling water temperature and $T_{w, i n}$ is the inlet cooling water temperature [1].

\section{Proposed modification of the Wilson plot method}

The determination of the HTC on the cooling side is based on the change in thermal resistance for different conditions (fluid velocity and temperature). The modification considers the presumption of validity of the
Nusselt theory for calculation of the HTC on the condensation side. The thermal resistance on the condensation side varies and it is part of the calculation.

\subsection{Non-dimensional parameters of the heat exchangers}

\section{Reynolds Number}

The Reynolds number $R e$ is a function of the fluid flow rate. The mathematical formula for the Reynolds number is provided in Eq. (10). The ratio represents momentum to viscous forces, where $v$ is the fluid velocity, $D$ is characteristic diameter and $v$ is the kinematic viscosity [4].

$$
R e=\frac{v \cdot D}{v}
$$

\section{Prandtl Number}

The Prandtl number $\operatorname{Pr}$ is a function of two important physical properties (thermal and momentum). The Prandtl number may be seen as the ratio of the rate that viscous forces penetrate the material to the rate that thermal energy penetrates the material [4]. In Eq. (11), $\mu$ is the dynamic viscosity, $c_{p}$ the material heat capacity and $k$ is thermal conductivity.

$$
\operatorname{Pr}=\frac{\mu \cdot c_{p}}{k}
$$

\section{Nusselt Number}

The Nusselt number $N u$ is equal to the dimensionless temperature gradient at the surface and it essentially provides a measure of the convective heat transfer. The Nusselt number may be viewed as the ratio of the conduction resistance of a material to the convection resistance of the same material [4].

$$
N u=\frac{h \cdot D}{k}
$$

\section{Nusselt Number Correlations}

In single phase fluid flow heat transfer, the Nusselt number is generally represented by a pragmatic expression in the form as seen in (13). The term $\left(\mu / \mu_{s}\right)$ is accountable for the variable viscosity effect for the case that the viscosity varies from the centre of the tube towards the tube wall [4].

$$
N u=C \cdot \operatorname{Re}^{n} \cdot \operatorname{Pr}^{m} \cdot\left(\frac{\mu}{\mu_{s}}\right)^{0.14}
$$

\subsection{Derivation of the proposed modification}

The overall thermal resistance $R_{o v}$ (Eq. (2)) for the described shell-and-tube condenser can be rewritten as 


$$
R_{o v}=\frac{1}{h_{c} \cdot A_{i}}+\frac{\ln \left(d_{o} / d_{i}\right)}{2 \cdot \pi \cdot k_{t} \cdot L_{t}}+\frac{1}{h_{w} \cdot A_{o}}
$$

where $h_{c}$ and $h_{w}$ are the condensation and cooling water HTCs, $d_{i}$ and $d_{o}$ are the inner and outer tube diameters, $k_{t}$ is the tube thermal conductivity, $L_{t}$ is the tube length and $A_{i}$ and $A_{o}$ are the inner and outer tube surface areas, respectively. By combining Eq. (8) and (14) is given

$$
\frac{1}{U \cdot A}=\frac{1}{h_{c} \cdot A_{i}}+\frac{\ln \left(d_{o} / d_{i}\right)}{2 \cdot \pi \cdot k_{t} \cdot L_{t}}+\frac{1}{h_{w} \cdot A_{o}}
$$

where $h_{w}$, can be expressed combining Eq. (12) and (13)

$$
h_{w}=\frac{k_{w}}{D} \cdot C \cdot \operatorname{Re}^{n} \cdot \operatorname{Pr}^{m} \cdot\left(\frac{\mu}{\mu_{s}}\right)^{0.14}
$$

and $h_{c}$ is defined by the Nusselt condensation theory [5], [6] as

$$
h_{c}=0.943\left[\frac{\rho_{L} g\left(\rho_{L}-\rho_{p}\right) h_{f g}^{\prime} k_{L}^{3}}{\mu_{L} \Delta T_{s a t} L}\right]^{1 / 4}
$$

where $\rho_{L}$ is the density of the condensate, $\rho_{p}$ is the density of the water vapour, $h_{f g}^{\prime}$ is the latent heat of condensation, $k_{L}$ is the thermal conductivity of the condensate, $\mu_{L}$ is the dynamic viscosity of the condensate, $\Delta T_{\text {sat }}$ is the saturation and wall temperature difference, $L$ is the wall length. By a substitution of terms in (8) and (16) to equation (15) is given

$$
\begin{aligned}
\frac{1}{\left(\frac{Q}{A \cdot \Delta T_{\log }}\right) \cdot A}= & \frac{1}{h_{c} \cdot A_{i}}+\frac{\ln \left(d_{e} / d_{i}\right)}{2 \cdot \pi \cdot \lambda_{s} \cdot L_{s}} \\
& +\frac{1}{\frac{k_{w}}{D} \cdot C \cdot \operatorname{Re}^{n} \cdot \operatorname{Pr}^{m} \cdot\left(\frac{\mu}{\mu_{s}}\right)^{0.14} \cdot A_{o}}
\end{aligned}
$$

It is possible to write Eq. (17) in linear form $Y=a \cdot X$

$$
\begin{aligned}
& \left(\frac{\Delta T_{\log }}{Q}-\frac{1}{h_{c} \cdot A_{i}}-\frac{\ln \left(d_{o} / d_{i}\right)}{2 \cdot \pi \cdot \lambda_{s} \cdot L_{s}}\right) \\
& =\frac{1}{C} \cdot \frac{1}{\frac{k_{w}}{D} \cdot \operatorname{Re}^{n} \cdot \operatorname{Pr}^{m} \cdot\left(\frac{\mu}{\mu_{s}}\right)^{0.14} \cdot A_{o}}
\end{aligned}
$$

Where the terms $Y, a$ and $X$ have the following forms

$$
\begin{gathered}
Y=\left(\frac{\Delta T_{\log }}{Q}-\frac{1}{h_{c} \cdot A_{i}}-\frac{\ln \left(d_{o} / d_{i}\right)}{2 \cdot \pi \cdot \lambda_{s} \cdot L_{s}}\right) ; \\
a=\frac{1}{C} ; X=\frac{1}{\frac{k_{w}}{D} \cdot \operatorname{Re}^{n} \cdot \operatorname{Pr}^{m} \cdot\left(\frac{\mu}{\mu_{s}}\right)^{0.14} \cdot A_{o}}
\end{gathered}
$$

The setting of $Y$ and $X$ values given for the set of experimental data can be fitted by the linear regression for an estimated value of the coefficient $n$. The value for the coefficient $m$ is set at 0.33 in accordance with standard practice in many transfer processes. The $X$ and $Y$ regression starts with an initial $n$ value. The $C$ coefficient is found based on a linear regression with the highest coefficient of determination for various values of the parameter $n$.

\section{Measurements}

Measurements of the operating parameters required for the calculation were carried out for two sizes of the exchanger heat transfer area, for the original number of 49 tubes and for a changed heat transfer area of 21 tubes with 28 tubes sealed off. The inlet steam velocity in both cases was maintained between 2 and $3.5 \mathrm{~m} / \mathrm{s}$. The steam is saturated at the atmospheric pressure. There were measured in 59 different operating states with changes in the cooling water flow and the cooling water temperature. The inlet cooling water temperature ranged between 60 and $85^{\circ} \mathrm{C}$, the outlet temperature between 80 and $95^{\circ} \mathrm{C}$. The cooling water flow rate was regulated by a circulating pump set to a Reynolds number value ranging from 1000 to 8000 . The heat exchanger performance was from 14 to $56 \mathrm{~kW}$, which corresponds with the amount of condensed steam between 21 and 90 $\mathrm{kg} / \mathrm{h}$, where the smaller values are related to the measurement with 21 tubes and the higher values to the measurement with 49 tubes. The condensate film thickness was calculated and it ranged from 0.063 to $0.11 \mathrm{~mm}$, which corresponds to a Reynolds number from 38 to 183 confirming the wavy-laminar condensate film flow.

\section{Results}

The result of the dependence $Y=a \cdot X$ introduced in Eq. (19) is shown in Fig. 4. The values were fitted by a linear regression with the highest coefficient of determination.

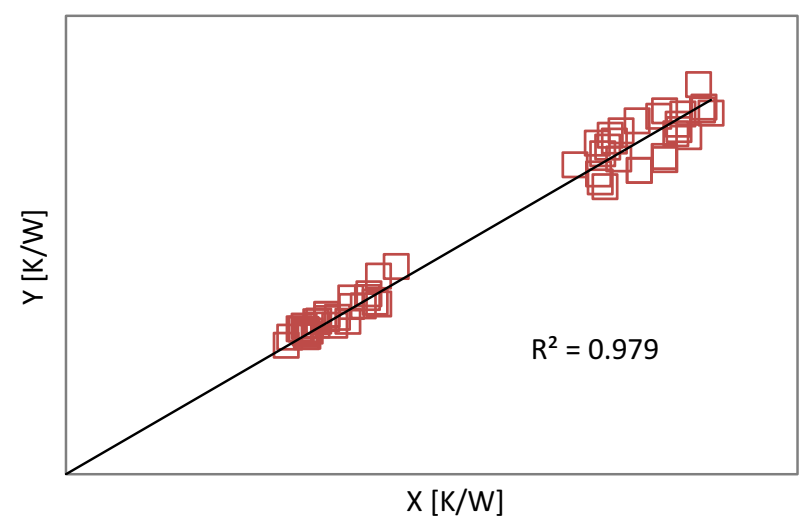

Fig. 4. Linear regression of thermal resistance according to the Wilson Plot method

In Fig. 4, there are two groups of points which differ in the number of tubes utilized (49 resp. 21). This is due to the significant difference in heat exchanger performance caused using different heat transfer surfaces. Based on the obtained linear regression, it is evident that the number of cooled tubes in the heat exchanger has no apparent effect on the dependency derived from the balance of heat resistance respective on the heat transfer in the shell-side of the heat exchanger. The coefficients evaluated from the linear regression are as follows

$$
n=0.56 ; m=0.33 ; C=0.2702
$$


The resulting equation for the cooling water side determined by the Wilson plot method has the form

$$
N u=0.270 \operatorname{Re}^{0.56} \operatorname{Pr}^{0.33}\left(\frac{\mu}{\mu_{s}}\right)^{0.14}
$$

Fig. 5 shows a comparison of the measured values of the HTC with the calculated values by the proposed equation. A correspondence between the calculated and experimentally determined values fits within the range of $\pm 8 \%$.

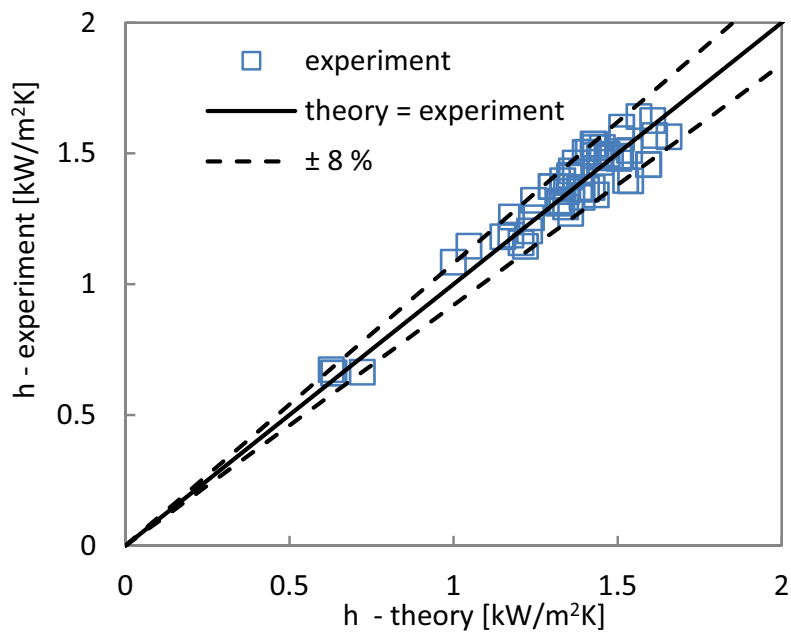

Fig. 5. Comparison of HTC experimental values with the results calculated by the proposed equation

\section{Discussion}

The proposed criterion equation is compared with the most commonly used theoretical methods - the methods by Kern, Bell-Delaware and Stream flow analysis (see Table 1). These methods are described in detail in [6]. For simplicity, the term $\left(\frac{\mu}{\mu_{s}}\right)^{0.14}$ is not shown in the table.

The proposed coefficients $C$ and $n$ reach similar values as the coefficients used in the theoretical methods. Fig. 6 shows that the proposed equation achieves good agreement with the experimental results and also with the Bell-Delaware method and Stream flow analysis. The Kern method does not take into account the heat exchanger geometry, e.g. manufacturing clearances and resulting leakages, and it gives higher values.

\section{Conclusion}

A modification of the Wilson plot method for shell-andtube condensers was proposed. The modification is based on the validation of the Nusselt theory for calculation of the HTC on the condensation side. The thermal resistance on the condensation side varies depending on different conditions of the total heat transfer process and is part of the calculation. It is possible to improve the determination accuracy of the convection coefficients using the proposed modification.

For the described heat exchanger, the criterion

Table 1 Comparison of criterion equation for calculation of the Nusselt number

\begin{tabular}{|l|l|l|}
\hline Equation & $\mathbf{N u}=\boldsymbol{C} \cdot \boldsymbol{R e}^{\boldsymbol{n}} \cdot \boldsymbol{P r}^{\mathbf{m}}$ & note \\
\hline Proposed & $N u=0.270 \cdot \operatorname{Re}^{0.56} \cdot \operatorname{Pr}^{0.33}$ & valid for the described exchanger \\
\hline Kern & $N u=0.36 \cdot \operatorname{Re}^{0.55} \cdot \operatorname{Pr}^{0.33}$ & it does not take into account the specific geometry \\
\hline Bell-Delaware & $N u=0.273 \cdot \operatorname{Re}^{0.635} \cdot \operatorname{Pr}^{0.34} \cdot \mathrm{J}$ & $\begin{array}{l}\mathrm{J} \text { is a correction coefficient for baffle geometry and } \\
\text { manufacturing accuracy }\end{array}$ \\
\hline Stream flow analysis & $N u=0.273 \cdot \operatorname{Re}_{c r}^{0.635} \cdot \operatorname{Pr}^{0.34}$ & $\begin{array}{l}\operatorname{Re} e_{c r}=F_{c r} \cdot R e, \text { where } F_{c r} \text { is a correction coefficient for } \\
\text { idealized fluid flow }\end{array}$ \\
\hline
\end{tabular}

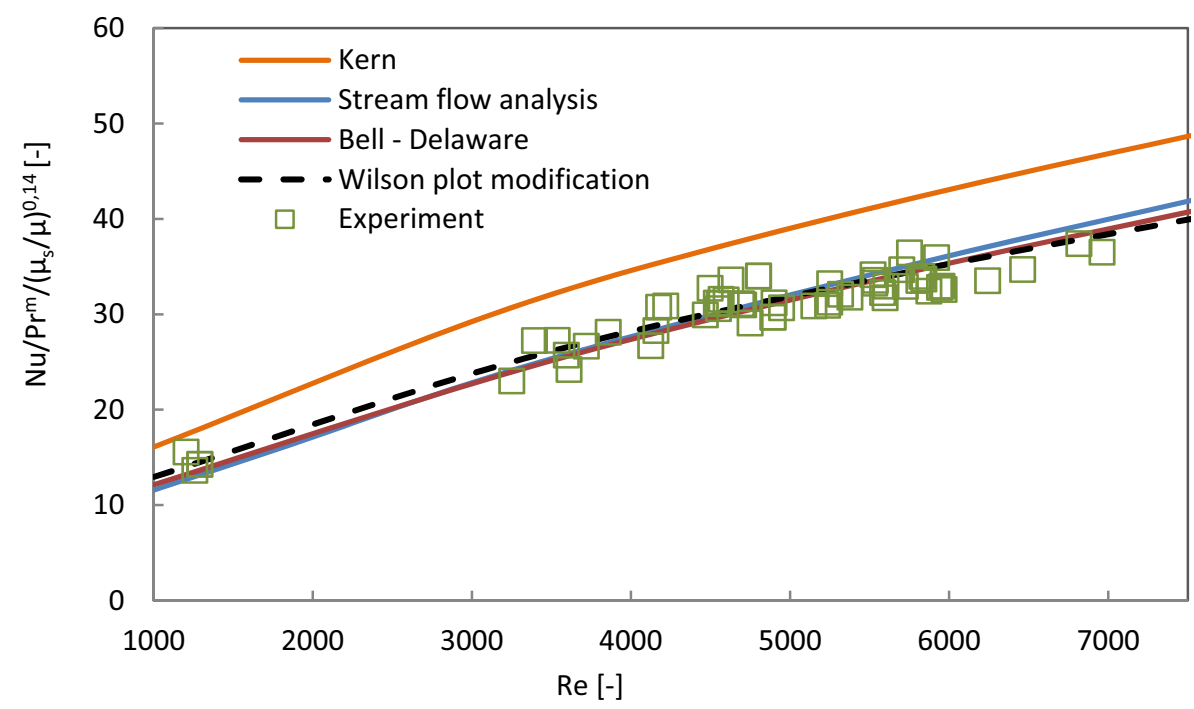

Fig. 6. Comparison of methods for the calculation of the HTC 
equation for the calculation of the Nusselt number was proposed. The theoretical results of the proposed equation were compared with the measured values. Correspondence between the theoretically and the experimentally determined values is located in the range of $\pm 8 \%$. The proposed coefficients $\mathrm{C}$ and $\mathrm{n}$ reach similar values as the coefficients found in the most commonly used theoretical methods. The proposed equation achieves better agreement with the experimental results as well as good compliance with the Bell-Delaware method and Stream flow analysis. The Kern method does not take into account the heat exchanger geometry and its results have higher values take into account the heat exchanger geometry and Stream flow analysis.

The modified method for the determination of the shell-side HTC was used in the subsequent research of the conditions of steam-air mixture condensation in the tubes, where the effect of noncondesable air on the condensation process was analysed.

This work has been supported by Norway Grants 2009-2014, project ID: NF-CZ08-OV-1-003-2015 and the Grant Agency of the Czech Technical University in Prague, grant no. SGS 14/183.

\section{Nomenclature}

A heat transfer area $\left(\mathrm{m}^{2}\right)$

C constant of geometry (-)

c specific heat capacity $(\mathrm{J} / \mathrm{kgK})$

d diameter $(\mathrm{m})$

D characteristic diameter (m)

g gravitational acceleration $\left(\mathrm{m} / \mathrm{s}^{2}\right)$

$\mathrm{h}$ convection coefficient $\left(\mathrm{W} / \mathrm{m}^{2} \mathrm{~K}\right)$

$\mathrm{h}_{\mathrm{fg}} \quad$ latent heat of condensation $(\mathrm{kJ} / \mathrm{kg})$

$\mathrm{k}$ thermal conductivity $(\mathrm{W} / \mathrm{mK})$

$\mathrm{L}$ tube length (m)

$\Delta \mathrm{T}_{\log }$ logarithmic mean temperature difference $(\mathrm{K})$

$\mathrm{M}$ mass flow rate $(\mathrm{kg} / \mathrm{s})$

$\mathrm{Nu}$ Nusselt number (-)

Pr Prandtl number (-)

$\mathrm{R}$ thermal resistance $(\mathrm{K} / \mathrm{W})$

Re Reynolds number (-)

$\mathrm{Q}$ rate of heat transfer (W)

$\mathrm{S}$ flow cross-section $\left(\mathrm{m}^{2}\right)$

$\mathrm{T}$ temperature $(\mathrm{K})$

$\mathrm{U}$ overall heat transfer coefficient $\left(\mathrm{W} / \mathrm{m}^{2} \mathrm{~K}\right)$

v velocity $(\mathrm{m} / \mathrm{s})$

$\mu \quad$ dynamic viscosity $(\mathrm{Pa} \cdot \mathrm{s})$

$v \quad$ kinematic viscosity $\left(\mathrm{m}^{2} / \mathrm{s}\right)$

\footnotetext{
Subscripts

f fluid

i inner

in inlet

1 liquid

o outer

out outlet

ov overall

$\mathrm{s}$ wall

$\mathrm{t}$ tube

w water
}

\section{References}

1. J. Fernández-Seara, F. J. Uhía, J. Sieres, A. Campo, Applied Thermal Engineering 27, 2745 (2007).

2. J. Havlik, T. Dlouhy, Acta Polytechnica 55, 306 (2015).

3. P. Kracik, J. Pospisil, Acta Polytechnica 55, 329 (2015).

4. V. R. Naik, V. K. Matawala, IJEAT 2, 362 (2013).

5. F. Hewitt, G. L. Shires, T. R. Bott, Process Heat Transfer (Begell House, New York, 2000).

6. F. P. Incropera et al., Principles of Heat and Mass Transfer (John Whiley, Singapore, 2013). 